\title{
Hope for UNCSTD in New York
}

David Dickson reports from New York on the third meeting of the preparatory committee for the United Nations Conference on science and technology for development

With less than seven months to go until the United Nations Conference on Science and Technology for Development (UNCSTD) opens in Vienna the political pace of preparations is beginning to heat up with indications that the conference may not turn out quite so unproductive as some have been fearing.

The most positive indication, according to a number of delegates attending the third meeting of the conference's preparatory committee, which opened in New York last week, is a new draft preliminary programme of action prepared by the conference secretariat.

The new draft, although still felt by many to suffer a number of important omissions-such as adequate discussion of the role of women in development, or the need for appropriate technologies-is widely accepted as a major improvement on earlier versions, which had been little more than the compilation of suggestions made in national and regional papers.

In particular, the new draft contains -as the General Assembly of the United Nations has said that it should -a number of specific recommendations for action around which discussion is likely to focus in the months ahead.

Opening the committee meeting last week, Dr Joao Frank da Costa, Secretary-General of the conference said that it was often more difficult to specific action-oriented measures, and that he therefore suggested concentrating on the latter rather than the former.

In particular, Dr da Costa said it would he necessary to develop firmer guidelines on cooperation between developed and developing countries, while the developing countries themselves, for which UNCSTD was a "now or never opportunity", should investigate ways of increasing their collective selfreliance.

The preliminary draft programme of action, which will be revised following comments by delegates at the New York meeting, contains both a theoretical and conceptual framework for further actions based largely on the outcome of debates, within the UN system, on the shape of the new international economic order, as well as over one hundred concrete measures for action at all levels.

Most of the recommendations are relatively uncontroversial. They include the suggestion that the developed countries increase the amount of money they spend on research into the problems of developing countries, and that the latter should establish national science and technology policies-drawn up and executed by governments, though with the advice of broadly based national science and technology councils representing all sectors of elaborate principles than to elaborate society-and establish institutions for assessing the impact of transferred technology.

More likely to generate controversy are recommendations which would involve setting up new international funds. The draft, for example, suggests that developing countries should establish a common science and technology fund "to which the most prosperous among them should contribute more generously", and that consideration also be given to a "risk capital fund" associated with existing financial institutions within the UN system.

Equally controversial are suggestions that to go beyond the domain of science and technology to comment on more overtly political issues. Paragraph 11.12 , for example, suggests that in parallel to mobilising science and technology for development, "countries should introduce internal structural policies such as social reforms, redistribution of income and so on, as appropriate, so as to ensure that the application of science and technology does not result in social tensions".

How many such suggestions will survive the revision process remains to be seen. Of particular interest is whether the developing countries, through the group of 77 , will be able to agree on a common set of demands. A working party established last week by the group is said to have had initial difficulty reaching a consensus. But the more coherent their position, according to observers in New York, the more likely that controversial issues will stay on the UNCSTD agenda.

\section{US paper stresses modernisation and meeting basic human needs}

THE modernisation of developing economies, and meeting the basic human needs of developing country populations are the two over-riding objectives in applying science and technology to development, according to the US national paper for UNCSTD.

In the introduction to the paper, Father Theodore Hesburgh, previously president of Notre Dame University and chairman of the US delegation to the conference, says that these two goals are not mutually exclusive or incompatible. "The fulfilment of basic needs and the process of economic moderation can proceed simultaneously in a mutually enforcing relationship," says Father Hesburgh.

The US paper, which has gone through numerous drafts and is yet to be officially released, describes the role played by science and technology in the growth of the US economy, as well as the US's experience in applying scientific and technological expertise to the problems of development in other nations.

The paper points out that President Carter has made scientific and technological cooperation a key element of the US's relationship with other countries, particularly in the developing world. It says that the success of the developmental process in other nations is "very much in the US interests."

The paper lists recommendations for action in six areas:

- Improving the capacity of industrialised countries to assist developing countries upgrade their scientific and technological skills;

- Assisting the development of education and training programmes;

- Encouraging collaborative research between scientists and engineers from both developed and developing nations on global problems such as food, water and health;
- Helping to overcome obstacles to developing countries' access to scientific and technological information;

- Strengthening the links between the research communities of developed and developing nations, including joint research and problem solving;

- Building a more effective UN system for science and technology.

The US paper puts forward the Foundation for International Technological Cooperation, which has been proposed by President Carter, as one way in which scientists from the developed and developing nations could work together, and suggests that the UN conference "should encourage the establishment of similar institutions in other countries".

The paper also says that the many useful science and technology activities within the UN system need a central focal point and policy direction, although, it adds, not a new entity. 